J. Dairy Sci. 102:1885-1885

https://doi.org/10.3168/jds.2019-102-2-1885

(๑) American Dairy Science Association ${ }^{\circledR}, 2019$.

\title{
Erratum to "Effects of applying Lactobacillus helveticus H9 as adjunct starter culture in yogurt fermentation and storage" (J. Dairy Sci. 102:223-235)
}

Tingting Zhou, ${ }^{1,2}$ Rui Huo, ${ }^{1,2}$ Lai-Yu Kwok, ${ }^{1,2}$ Changkun Li, ${ }^{1,2}$ Yuzhu Ma, ${ }^{1,2}$ Zhihui Mi, ${ }^{1,2}$ and Yongfu Chen ${ }^{1,2}$

${ }^{1}$ Key Laboratory of Dairy Biotechnology and Engineering, Ministry of Education P. R. C., Inner Mongolia Agricultural University, Huhhot 010018, P. R. China

${ }^{2}$ Key Laboratory of Dairy Products Processing, Ministry of Agriculture P. R. C., Inner Mongolia Agricultural University, Huhhot 010018, P. R. China

The affiliations in this paper were incorrect; the correct affiliations are shown above.

The journal regrets the error.

\section{REFERENCES}

Zhou, T., R. Huo, L.-Y. Kwok, C. Li, Y. Ma, Z. Mi, and Y. Chen. 2019. Effects of applying Lactobacillus helveticus H9 as adjunct starter culture in yogurt fermentation and storage. J. Dairy Sci. 102(1):223-235. https://doi.org/10.3168/jds.2018-14602. 